\title{
IMMOBILIZATION OF $\mathrm{Cu}^{2+}$ USING STABILIZED NANO ZERO VALENT IRON PARTICLES IN CONTAMINATED AQUEOUS SOLUTIONS
}

\begin{abstract}
Batch kinetic experiments were conducted to investigate the feasibility of using carboxylmethyl cellulose (CMC)-stabilized nano zero valent iron (nZVI) particles for immobilization of $\mathrm{Cu}^{2+}$ in water. The effects of nZVI concentration, $\mathrm{pH}$, and initial concentration of $\mathrm{Cu}^{2+}$ have been studied. $\mathrm{Cu}^{2+}$ immobilization increased from $59.10 \%$ to $98.10 \%$ as the nZVI concentration increased from 0.2 to $2.0 \mathrm{~g} / \mathrm{l}$. The adsorption kinetics of $\mathrm{Cu}^{2+}$ ions was fitted to a pseudo-second order model and both Langmuir and Freundlich isotherms fit experimental data. SEM-EDX indicates that slightly porous and fragile particles were formed due to the corrosion on the nZVI surface.
\end{abstract}

\section{INTRODUCTION}

Immobilization of heavy metal contaminants from aqueous main streams is one of the most important environment issues being monitored by researchers and local authorities [1]. Increased use of metals and chemicals in industries related to mineral and metallurgical processing, pulp, paper and wood preserving, fertilizers, and petroleum refining, as well as the excessive use of copper-based agrichemicals, significantly result in the contamination of water due to heavy metal toxicity $[2,3]$. Copper, arsenic, mercury, and chromium are relatively widespread in the environment. These elements have been recognized as the most hazardous toxic compounds that can adversely affect humans, animals, and various life forms even in trace amounts [2-4].

Over the years, researchers have developed techniques for the immobilization of metal ions from aqueous solutions. Remediation techniques for groundwater have

*School of Industrial Technology, Universiti Sains Malaysia, 11800, P. Pinang, Malaysia; corresponding author Norli Ismail, e-mail: norlii@usm.my

**School of Chemical Engineering, Universiti Sains Malaysia, 14300 Nibong Tebal, P. Pinang, Malaysia. 
largely followed the in situ reduction and precipitation/immobilization system [2, 5]. Research teams suggest application of a wide variety of adsorbents in the adsorption process to overcome this environmental issue. Some previous developments have proposed use of biomaterials as adsorbents. These biomaterials include coconut husk [6], meranti sawdust [7-9], rice straw [10] and oil palm tree-derived biomasses [11].

Meanwhile, the development of nano zero valent iron (nZVI) particles has widened the variety of adsorbents used in targeting the pollutants in contaminated groundwater $[4,12,13]$. Compared with conventional adsorbents, nZVI particles have long been recognized as excellent electron donors for environmental applications. These particles can be synthesized easily at lower cost, a lesser volume of the nanoparticles suspension is required, and the adsorption capacity is high due to a larger surface area [14]. However, the natural tendency of nZVI particles to aggregate due to their magnetic properties may severely limit the delivery to the target contaminants $[15,16]$. To determine a solution to this problem, enhancements of reaction rates by the manipulation of the size and transport of the nZVI particles through a coating process using a stabilizer, such as polymer, have been investigated [16-19].

To date, majority of published studies focused on halogenated organic compounds such tetrachloroethene, trichloroethene, carbon tetrachloride, organochlorine pesticides (e.g. dichlorodiphenyltrichloroethane and lindane), nitro aromatic compounds, etc., [16-23]. However, recent research suggests that copper $(\mathrm{Cu})$ ions can also be reduced by the nZVI particles. Rangsivek and Jekel [26] prepared macroscale ZVI as scrap iron from a steel cylinder and studied processes, rate, and capacities of $\mathrm{Cu}^{2+}$ uptake in simulated storm water runoff. Their results demonstrate reductive mechanism followed by adsorption/co-precipitation processes. A substantial portion of $\mathrm{Cu}^{2+}$ is reduced and transformed to insoluble form of $\mathrm{Cu}$ and $\mathrm{Cu}_{2} \mathrm{O}$. Promising results were also obtained from Karabelli et al. [3]. They found that the nZVI fast kinetics and strong uptake ability could reduce $\mathrm{Cu}^{2+}$ to $\mathrm{Cu}$ in the range of concentration $10-200 \mathrm{mg} / \mathrm{l}$.

The objective of the present study was to evaluate the efficiency of carboxylmethyl cellulose (CMC) as a dispersant for nZVI suspension. The reactivity of pre-synthesis CMC-stabilized nZVI particles for immobilization of $\mathrm{Cu}^{2+}$ as representative metal species in groundwater was also assessed. The uptake experiments included determination of the effects of concentration of nZVI suspension, $\mathrm{pH}$, and initial concentration of contaminants injected in the stabilized nZVI system using equilibrium, kinetic and isotherm tests.

\section{EXPERIMENTAL}

Materials. Chemicals used for the experiment were of analytical and laboratory reagent grades. Ultrapure, degassed, and deionized (DI) water was used in the stock solution preparation. $\mathrm{FeSO}_{4} \cdot 7 \mathrm{H}_{2} \mathrm{O}$ was purchased from Fisher Scientific, CMC 
$(\mathrm{MW}=90 \mathrm{~K})$ from Acros Organic, sodium borohydride $\left(\mathrm{NaBH}_{4}\right)$ and copper sulfate pentahydrate $\left(\mathrm{CuSO}_{4} \cdot 5 \mathrm{H}_{2} \mathrm{O}\right)$ from Sigma Aldrich. To maintain the reaction of CMC molecules, the stock solution was stored in a cold room at the temperature below $4{ }^{\circ} \mathrm{C}$. Prior to every experiment, the DI water and CMC stock were purged with purified nitrogen for one hour to remove dissolved oxygen.

Preparation of $n Z V I$ particles. Pre-synthesis CMC-stabilized nZVI was a tailored method after He et al. [19]. A one liter three-necked flask was attached to a vacuum line. A mechanical stirrer with a Teflon blade was used throughout the experiment to prevent adherence of any nZVI particle to the steel. This step prevented the resultant nZVI particles to agglomerate so that the highest reactivity can be obtained. The flask was half-submerged in an ice bath container to maintain the temperature at $10-18{ }^{\circ} \mathrm{C}$. Fresh stock $(10 \mathrm{ml})$ of $0.21 \mathrm{M} \mathrm{FeSO}_{4} \cdot 7 \mathrm{H}_{2} \mathrm{O}$ acted as a cation precursor for the nZVI particles, and 0.9 wt. \% water soluble $\mathrm{CMC}$ was employed. Fe concentration used in the present study varied from $0.2-2.0 \mathrm{~g} / \mathrm{l}$. The prepared precursor CMC solution was slowly reduced by a stoichiometric amount of $10 \mathrm{ml} \mathrm{NaBH}$ to promote FeO. Black nZVI particles appeared immediately. The reaction continued until hydrogen bubbles totally disappeared. To ensure homogeneous mixing, the suspension was stirred at $220 \mathrm{rpm}$ under anoxic condition. The synthesized nanoparticle suspension was then sampled and immediately used for the $\mathrm{Cu}^{2+}$ immobilization process.

Immobilization experiments in aqueous solution. An original stock solution of $500 \mathrm{mg} / 1 \mathrm{Cu}^{2+}$ was prepared by dissolving $\mathrm{CuSO}_{4} \cdot 5 \mathrm{H}_{2} \mathrm{O}$ in ultra pure water. The CMC-stabilized nZVI particles of $0.2-2.0 \mathrm{~g} / \mathrm{l}$ were then tested in batch experiments to reduce $\mathrm{Cu}^{2+}$ in water. The immobilization test was initiated by injecting $10-30 \mathrm{mg} / 1$ $\mathrm{Cu}^{2+}$ stock solution in $12 \mathrm{ml}$ of nZVI particle suspension into $13 \mathrm{ml}$ glass vials. The solution was made up to the required $\mathrm{pH}(2.5-7.5)$. Zero headspace was maintained in all vials to mimic the real condition in an aqueous stream. The injected suspension was then agitated on a rotator at the speed of $150 \mathrm{rpm}$. Samples were periodically collected at $0,15,30,60,120,180$, and $240 \mathrm{~min}$. Control experiments were conducted under similar experimental conditions. The samples were transferred to centrifuge tubes, centrifuged at $4000 \mathrm{rpm}$ for $10 \mathrm{~min}$, and filtered immediately through $0.45 \mu \mathrm{m}$ Whatman membrane filter paper before further analyses. Copper concentrations were determined using an atomic absorption spectrophotometer (Analyst 100 PerkinElmer). All the experimental points were performed in duplicates to assure data quality.

The percentage of pollutants immobilized by the adsorbent was calculated using the equation:

$$
\text { Reduction }=\frac{C_{0}-C_{e}}{C_{0}} \times 100 \%
$$

To calculate the reduction capacity for nZVI particles, the mass balance calculation equation was used: 


$$
q=\frac{\left(C_{0}-C_{e}\right) V}{W}
$$

where $C_{0}$ and $C_{e}$ are the initial and equilibrium concentrations of $\mathrm{Cu}^{2+}$ ions $(\mathrm{mg} / \mathrm{l})$ in the solution, $q$ is the reduction capacity $(\mathrm{mg} / \mathrm{g}), V$ is the volume of the solution (l), and $W$ is the mass of the nZVI particles $(\mathrm{g})$.

Adsorption behavior of $\mathrm{Cu}^{2+}$ onto $\mathrm{nZVI}$ (isotherm studies). Adsorption isotherm reveals a specific relation between mass adsorbate adsorbed per unit weight of adsorbent in equilibrium and liquid phase equilibrium concentration of adsorbate [21]. Classical Langmuir and Freundlich models were used to interpret the immobilization capacity of $\mathrm{Cu}^{2+}$ by CMC-stabilized nZVI particles. Langmuir proposed the following the model:

$$
\frac{C_{e}}{A_{m}}=\frac{1}{K_{L}} \times \frac{1}{b}+\frac{1}{b} C_{e}
$$

where $C_{e}$ is the equilibrium concentration $(\mathrm{mg} / \mathrm{l}), A_{m}$ is the amount adsorbed per specified amount of adsorbent $(\mathrm{mg} / \mathrm{g}), K_{L}$ is the equilibrium constant $(\mathrm{mg} / \mathrm{g})$, and $b$ is the amount of adsorbate required to form a monolayer $(1 / \mathrm{mg})$. The values of $b$ and $K_{L}$ were determined by linear straight fitting of a plot $C_{e} / \mathrm{A}_{m}$ vs. $C_{e}$ according to respective equilibrium adsorption data. A further analysis of the Langmuir equation can be expressed in term of the separation factor, dimensionless equilibrium constant, [22] given by:

$$
R_{L}=\frac{1}{1+b C_{0}}
$$

The value of $R_{L}$ between 0 and 1 shows a favorable adsorption, while $R_{L}>1$ represents unfavorable adsorption; $R_{L}=1$ represents linear adsorption, while the adsorption process is irreversible if $R_{L}=0$ [7].

The Freundlich model can be applied for non-ideal sorption on heterogeneous surfaces and multilayer sorption. According to this model:

$$
\begin{gathered}
A_{m}=K_{F} C_{e}^{1 / n} \\
\lg A_{m}=\lg K_{F}+\frac{1}{n} \lg C_{e}
\end{gathered}
$$

where all the terms have the usual significance and $n$ is an empirical constant. Thus, a plot of $\log A_{\mathrm{m}} \mathrm{vs} . \log C_{e}$ should be a straight line with the slope $1 / n$ and intercept of $\log K_{F}$. The degree of nonlinearity between $\mathrm{Cu}^{2+}$ concentration and adsorption is determined by $n$ constant, $n>1$ representing favorable adsorption conditions [21].

To interpret the adsorption behavior of CMC-stabilized nZVI particles for immobilization of $\mathrm{Cu}^{2+}$ (adsorbent concentration $=1.0 \mathrm{~g} / 1, \mathrm{pH}=5.5$, initial $\mathrm{Cu}^{2+}$ concentra- 
tion $=7,10,15,20$ and $30 \mathrm{mg} / 1$, agitation duration $=240 \mathrm{~min}, \omega=150 \mathrm{rpm}$, and temperature $=30{ }^{\circ} \mathrm{C}$ ) have been set up. The equilibrium data were then fitted to the Langmuir and Freundlich isotherm models.

\section{RESULTS AND DISCUSSIONS}

\subsection{EFFECT OF nZVI CONCENTRATION}

The effects of adsorbent concentration in the immobilization of $\mathrm{Cu}^{2+}$ are shown in Fig. 1a. Four different concentrations of nZVI suspension were employed in the present study. An increase in the nZVI suspension resulted in significantly enhanced $\mathrm{Cu}^{2+}$ removal efficiency. Immobilization of $\mathrm{Cu}^{2+}$ by nZVI particles increased from $59.13 \%$ to $98.10 \%$ when the nZVI particles concentration increased from 0.2 to $2.0 \mathrm{~g} / 1$ over the period of $4 \mathrm{~h}$ under equilibrium conditions.
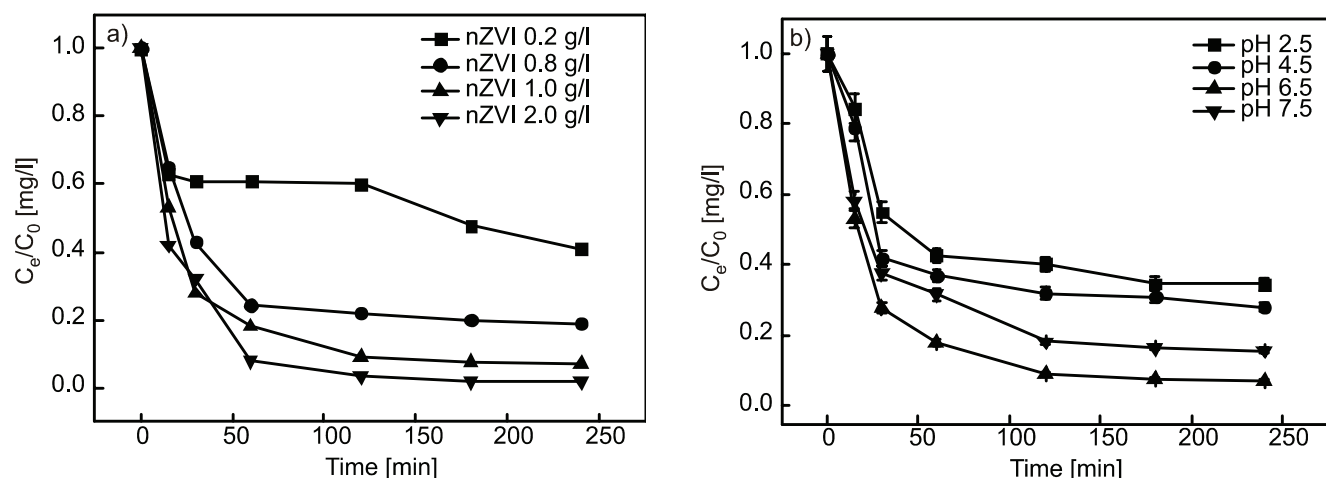

Fig. 1. Factors influencing $\mathrm{Cu}^{2+}$ immilization:

a) nZVI particles at various concentrations; $\left.\mathrm{Cu}^{2+}=10 \mathrm{mg} / \mathrm{l}, \mathrm{pH}=6.5, \mathrm{~b}\right) \mathrm{pH}, \mathrm{Cu}^{2+}=10 \mathrm{mg} / 1$, $\mathrm{nZVI}=1.0 \mathrm{~g} / \mathrm{l}, \mathrm{c})$ initial $\mathrm{Cu}^{2+}$ concentration; $\mathrm{nZVI}=1.0 \mathrm{~g} / \mathrm{l}, \mathrm{pH}=6.5$, agitation duration $=240 \mathrm{~min}, \omega=150 \mathrm{rpm}$, and $T=30^{\circ} \mathrm{C}$. For all figures the error bars represent $95 \%$ confidence intervals from duplicated experiments

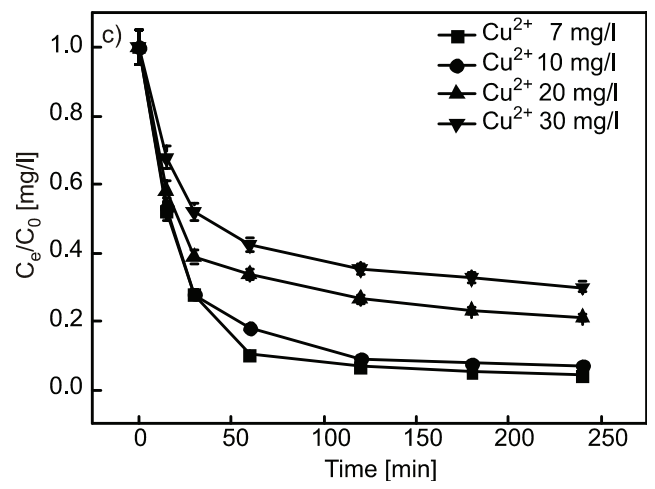

This enhancement corresponds to higher adsorbent concentration proportional to the increase in the number of active sites, resulting in improved $\mathrm{Cu}^{2+}$ immobilization. The uptake of $\mathrm{Cu}^{2+}$ by CMC-coated nZVI particles occurred on Fe surfaces, where 
$\mathrm{Cu}^{2+}$ ions formed four coordination bonds with two neighboring - $\mathrm{COOH}$ groups and possibly some with interior donor atoms [23, 24]. Ionizable groups likely formed due to the electrostatic repulsion between the trapped $\mathrm{Cu}^{2+}$ and a few free $-\mathrm{COO}$ groups from the $\mathrm{CMC}$ macromolecular skeleton [1]. This phenomenon further strengthens the binding of metal ions and increases $\mathrm{Cu}^{2+}$ removal through a redox process $[1,24]$. Furthermore, the availability of $\mathrm{FeOOH}$ groups at the solution-iron interface is consistent with previous findings $[3,25]$. This condition indicates that surface complexation to the uptake mechanism depends on the metallic ion under investigation.

The kinetic experimental data were fitted to both pseudo-first order (PFO) and pseudo-second order (PSO) equations. The PSO kinetic model obtained in the present study agrees with the results of earlier findings in which nano goethite and nano hematite were employed for the removal of $\mathrm{Cu}^{2+}$ [14]. However, Rangsivek and Jekel [26] reported that their experimental data followed a PFO rate law when $\mathrm{Cu}^{2+}$ was removed using the nZVI system employing kinetic and equilibrium tests. The conformity between experimental data and kinetic model predicted was based on the correlation coefficient (adjusted $R^{2}$ ). The adsorption kinetics fitted with PFO showed poor adjusted $R^{2}(0.7298-0.9820)$, while PSO yielded higher values of the correlation coefficient from $0.9390-0.9969$. The observed kinetic rate constants for PSO, $k$ values were evaluated and used to interpret the experimental results:

$$
\frac{d q}{d t}=k\left(q_{e}-q\right)^{2}
$$

After integrating Eq. (7) for the boundary conditions $t=0$ to $>0$ and $q=0$ to $>0$, and rearranging terms, the following linear equations will be obtained:

$$
\begin{gathered}
\frac{t}{q}=\frac{1}{k q_{e}{ }^{2}}+\frac{1}{q_{e}} \times t \\
h=k q_{e}^{2}
\end{gathered}
$$

where $q_{e}$ is the amount of initial concentration of $\mathrm{Cu}^{2+}$ (adsorbate) adsorbed at equilibrium per unit weight of nZVI particles $(\mathrm{mg} / \mathrm{g}), q$ - the amount of solute adsorbed at any time $(\mathrm{mg} / \mathrm{g})$ and $k$ - the PSO adsorption constant. The plot of $t / q$ vs. time of Eq. (8) yields a directly proportional relationship; $k$ value based on initial concentration of $\mathrm{Cu}^{2+}$ can be determined from the slope. Then, the intercept will give the $h$ value, which is the initial sorption rate $\left(\mathrm{mg} \cdot \mathrm{g}^{-1} \cdot \mathrm{min}^{-1}\right)$. The summary of the values are given in Table 1.

The $k$ values for the effect of nZVI concentration were determined $0.0101,0.0113$, 0.0120 and $0.0129 \mathrm{~g} \cdot \mathrm{mg}^{-1} \cdot \mathrm{min}^{-1}$ for concentrations of $0.2-2.0 \mathrm{~g} / \mathrm{l}$. The $h$ value was recorded at $0.3386-1.3296 \mathrm{mg} \cdot \mathrm{g}^{-1} \cdot \mathrm{min}^{-1}$. However, for non-stabilized nZVI particles the values of $k$ and $h$ were recorded much lower at $9.6158 \times 10^{-3} \mathrm{~g} \cdot \mathrm{mg}^{-1} \cdot \mathrm{min}^{-1}$ and $0.1543 \mathrm{mg} \cdot \mathrm{g}^{-1} \cdot \mathrm{min}^{-1}$. CMC-stabilized nZVI particles at the concentration of $1.0 \mathrm{~g} / 1$ 
immobilized $\mathrm{Cu}^{2+}$ around 1.2 times faster than their counterpart. Considerably, the $k$ value obtained is higher than that reported $\left(6.0267 \times 10^{-5} \mathrm{~g} \cdot \mathrm{mg}^{-1} \cdot \mathrm{min}^{-1}\right)$ where nano goethite particles were produced by the co-precipitation method at the concentration of $0.3 \mathrm{~g} / 1$ and with the initial $\mathrm{Cu}^{2+}$ concentration of $3.793 \mathrm{mg} / 1$ [14]. The concentration of CMC-stabilized nZVI suspension in this study was $\sim 3.3$ times higher than that used of Chen and $\mathrm{Li}$ [14] and the initial $\mathrm{Cu}^{2+}$ concentration of $10 \mathrm{mg} / \mathrm{l}$ in this study was 2.6 times higher than that $(3.793 \mathrm{mg} / \mathrm{l})$ by them. This could be due to stronger coordination bond formed between the stabilizer and iron ion of the precursor complex and electrostatic interactions [17]. Likely, its higher stability inhibit tendency to aggregate and increase the mass transfer to available surface site (nZVI) for $\mathrm{Cu}^{2+}$ immobilization, further increase the $k$ values. On the other hand, in the presence of CMC the small semi crystalline/amorphous particles contribute further higher $k$ values, when compared to granular polycrystalline particles of Chen and Li [14].

Table 1

PSO kinetic model for $\mathrm{Cu}^{2+}$ reduction in aqueous solution

\begin{tabular}{|c|c|c|c|}
\hline Parameters & $\begin{array}{c}k \\
{\left[\mathrm{~g} \cdot \mathrm{mg}^{-1} \mathrm{~g} \cdot \mathrm{min}^{-1}\right]}\end{array}$ & 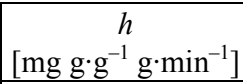 & Adj. $R^{2}$ \\
\hline $\begin{array}{l}\text { Non-stabilized nZVI }(1.0 \mathrm{~g} / \mathrm{l}) \\
\mathrm{pH}=6.5 \\
\text { initial concentration of } \mathrm{Cu}^{2+}=10 \mathrm{mg} / \mathrm{l}\end{array}$ & $9.6158 \times 10^{-3}$ & 0.1543 & 0.9390 \\
\hline $\begin{array}{l}\text { CMC-stabilized nZVI }(1.0 \mathrm{~g} / \mathrm{l}) \\
\mathrm{pH}=6.5 \\
\text { initial concentration of } \mathrm{Cu}^{2+}=10 \mathrm{mg} / \mathrm{l}\end{array}$ & 0.0120 & 1.1169 & 0.9967 \\
\hline $\begin{array}{l}\text { CMC-stabilized nZVI } \\
\text { Effect of nZVI concentration } \\
0.2 \mathrm{~g} / 1 \\
0.8 \mathrm{~g} / 1 \\
2.0 \mathrm{~g} / 1\end{array}$ & $\begin{array}{l}0.0101 \\
0.0113 \\
0.0129 \\
\end{array}$ & $\begin{array}{l}0.3386 \\
0.8019 \\
1.3296 \\
\end{array}$ & $\begin{array}{l}0.9459 \\
0.9939 \\
0.9969 \\
\end{array}$ \\
\hline $\begin{array}{l}\text { Effect of } \mathrm{pH} \\
\mathrm{pH}=2.5 \\
\mathrm{pH}=4.5 \\
\mathrm{pH}=7.5\end{array}$ & $\begin{array}{c}6.3034 \times 10^{-3} \\
8.5830 \times 10^{-3} \\
0.0107\end{array}$ & $\begin{array}{l}0.3258 \\
0.4937 \\
0.8239\end{array}$ & $\begin{array}{l}0.9619 \\
0.9794 \\
0.9953\end{array}$ \\
\hline $\begin{array}{l}\text { Effect of initial concentration of } \mathrm{Cu}^{2+} \\
7 \mathrm{mg} / \mathrm{l} \\
20 \mathrm{mg} / \mathrm{l} \\
30 \mathrm{mg} / \mathrm{l}\end{array}$ & $\begin{array}{c}0.0177 \\
6.6346 \times 10^{-3} \\
3.6942 \times 10^{-3} \\
\end{array}$ & $\begin{array}{l}0.8512 \\
1.7428 \\
1.7534 \\
\end{array}$ & $\begin{array}{l}0.9966 \\
0.9965 \\
0.9943 \\
\end{array}$ \\
\hline
\end{tabular}

\subsection{EFFECT OF INITIAL $\mathrm{pH}$}

The complex transformation mechanism of metal ions by nZVI particles is considerably affected by $\mathrm{pH}$ of the solution of adsorbate which is verified as a redox pro- 
cess [3, 26-28]. The $\mathrm{pH}$ dependence of adsorption of $\mathrm{Cu}^{2+}$ by nZVI particles was examined by varying $\mathrm{pH}$ in the range of 2.5-7.5 (Fig. 1b). This variation resulted in the removal of the immobilization of $\mathrm{Cu}^{2+}$ to $72.00 \%$ at $\mathrm{pH} 2-4.5$ and $93.00 \%$ at $6.5-7.5$. This behavior shows that nZVI particles are effective in acidic and neutral media. This result is partially similar to an earlier study on the sorption of other metal ions $\left(\mathrm{As}^{3+}\right.$ and $\left.\mathrm{As}^{5+}\right)$ by nZVI particles [4], which may be attributed to the protonation and deprotonation of both adsorbates and adsorbents [23]. From literature, $\mathrm{Cu}$ ions appear in various chemical forms depending on the $\mathrm{pH}$ of the aqueous medium. If the $\mathrm{pH}$ value is up to 6.5 , then the

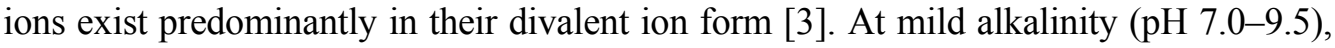
cationic compounds such as $\mathrm{Cu}(\mathrm{OH})^{+}, \mathrm{Cu}_{2}(\mathrm{OH})_{2}^{2+}$ and $\mathrm{Cu}_{3}(\mathrm{OH})_{4}^{2+}$ will be predominant. However, outside this range, $\mathrm{Cu}(\mathrm{OH})_{2}$ and other anionic species such as $\mathrm{Cu}(\mathrm{OH})_{3}$ and $\mathrm{Cu}(\mathrm{OH})_{4}^{2-}$ will become highly operative [3].

After 240 min reaction, the final $\mathrm{pH}$ values were recorded as $2.12,3.86,4.68$, and 4.91 for the initial $\mathrm{pH} 2.5,4.5,6.5$, and 7.5, respectively. Within the given $\mathrm{pH}$ ranges, $\mathrm{Cu}$ ions were expected to possess the divalent form during the experiment. When $\mathrm{Cu}^{2+}$ was injected, $\mathrm{pH}$ changed quickly from different initial $\mathrm{pH}$, and remained basically unchanged in the next reaction as shown in Fig. 1b. An acidic medium condition would further accelerate the corrosion of CMC-stabilized nZVI particles [29], enhancing $\mathrm{Cu}^{2+}$ immobilization. During the first $30 \mathrm{~min}, \mathrm{Cu}^{2+}$ removal was rapid at $\mathrm{pH} 6.5$ with the $k$ value of $0.0120 \mathrm{~g} \cdot \mathrm{mg}^{-1} \cdot \mathrm{min}^{-1}$ and $h=1.1169 \mathrm{mg} \cdot \mathrm{g}^{-1} \mathrm{~min}^{-1}$. This behavior indicates high reactivity of the nZVI particles. In contrast, at $\mathrm{pH} 7.5$ it exhibits a less rapid removal with $0.0107 \mathrm{~g} \cdot \mathrm{mg}^{-1} \cdot \mathrm{min}^{-1}$ and $0.8239 \mathrm{mg} \cdot \mathrm{g}^{-1} \cdot \mathrm{min}^{-1}$, respectively for values of $k$ and $h$. This phenomenon may be due to the formation of mixed nZVI and $\mathrm{Cu}$ oxyhyrides at higher $\mathrm{pH}$ values on the Fe surfaces [30]. In this case, $\mathrm{OH}^{-}$fairly became strong ligands and tended to compete for sorption sites in the high $\mathrm{pH}$ solution. A metastable equilibrium was established at the near plateau trends of the plots over the $240 \mathrm{~min}$ reaction. This result is probably due to the surface passivation of the particle being attributed as a consequence of reactivity loss $[5,29,31]$

\subsection{EFFECT OF INITIAL $\mathrm{Cu}^{2+}$ CONCENTRATION}

$\mathrm{Cu}^{2+}$ immobilization efficiency decreases with increasing initial $\mathrm{Cu}^{2+}$ concentration (Fig. 1c). The removed fraction was $95.80 \%$ for lowest concentration at $7 \mathrm{mg} / \mathrm{l}$ and $70.09 \%$ at initial concentration of $30 \mathrm{mg} / \mathrm{l}$ over the $240 \mathrm{~min}$ batch test by CMC-stabilized nZVI particles of $1.0 \mathrm{~g} / 1$.

The $k$ values range from $0.0177 \mathrm{~g} \cdot \mathrm{mg}^{-1} \cdot \mathrm{min}^{-1}$ at initial $7 \mathrm{mg} / 1 \mathrm{Cu}^{2+}$ to $3.6942 \times 10^{-3}$ $\mathrm{g} \cdot \mathrm{mg}^{-1} \cdot \mathrm{min}^{-1}$ at $30 \mathrm{mg} / 1 \mathrm{Cu}^{2+}$. The pre-synthesis $\mathrm{nZVI}$ particles in the presence of CMC yielded stable nanoparticles and enhanced reactive surfaces [19, 29], thus yield- 
ing higher $k$ values in comparison to non-stabilized nZVI (Table 1). In addition, redox mechanism in aqueous solution in which $\mathrm{Cu}^{2+}$ ions are reduced to metallic coppe, would be expected to transpire considering that $\mathrm{Cu}^{2+}$ is a strong oxidant and a well known passivator of $\mathrm{Fe}$. Therefore, as higher $\mathrm{Cu}^{2+}$ approaches the vicinity of nZVI particles, more Fe would be oxidized and lost, resulting to a decrease in the $k$ values [32].

\subsection{ADSORPTION BEHAVIOR OF nZVI ONTO $\mathrm{Cu}^{2+}$ (ISOTHERM STUDIES)}

The linear straight plots of Eqs. 6 and 8 illustrate the respective equilibrium adsorption data for Langmuir and Freundlich isotherms (Figs. 2a, b). The correlation coefficient and related adsorption isotherm constants of both isotherms were compared in Table 2.
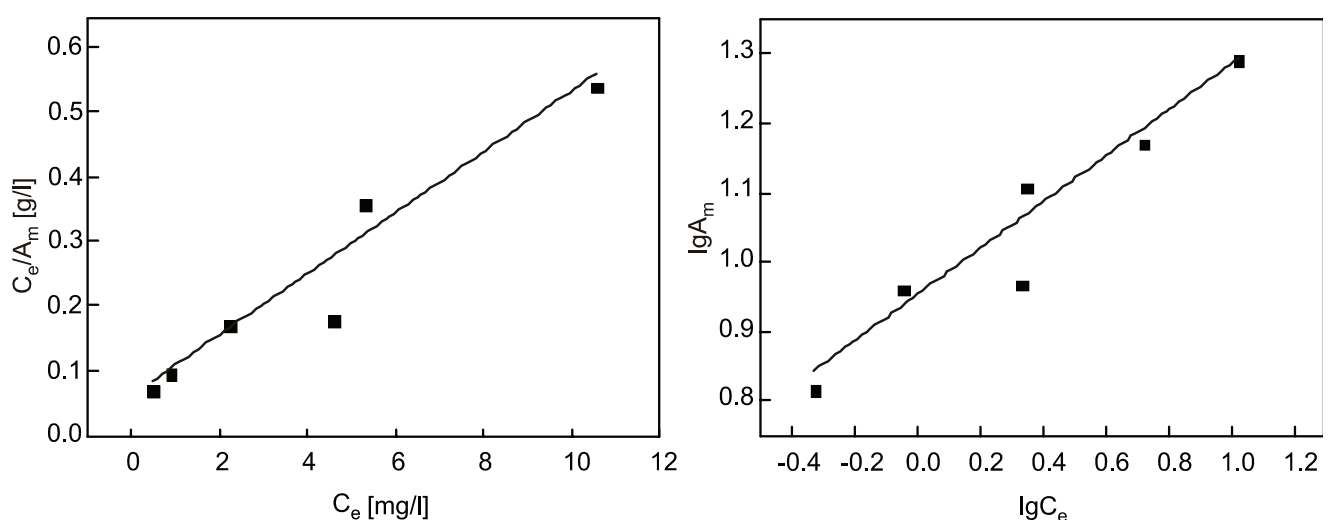

Fig. 2. Plots of Langmuir (a) and Freundlich (b) isotherms for the adsorption of $10 \mathrm{mg} / \mathrm{Cu}^{2+}$ by CMC-stabilized nZVI particles of $1.0 \mathrm{~g} / \mathrm{l}$ concentration

Table 2

$\mathrm{Cu}^{2+}$ adsorption parameters calculated based on the Langmuir and Freundlich isotherms

\begin{tabular}{|c|l|c|}
\hline Isotherm & \multicolumn{2}{|c|}{ Parameters } \\
\hline \multirow{5}{*}{ Langmuir } & $K_{L}, \mathrm{mg} / \mathrm{g}$ & 16.1499 \\
& $b, \mathrm{l} / \mathrm{mg}$ & 1.3008 \\
& Adj. $R^{2}$ & 0.9768 \\
\hline \multirow{3}{*}{ Freundlich } & $K_{F}, \mathrm{mg} / \mathrm{g},(\mathrm{l} / \mathrm{mg})^{1 / n}$ & 9.1559 \\
& $n$ & 3.0423 \\
& Adj. $R^{2}$ & 0.9353 \\
\hline
\end{tabular}

The plot of Langmuir isotherm shows a relatively higher regression coefficient (0.9768) as compared with that of the Freundlich isotherm (0.9353). However, a slight 
difference for adjusted $R^{2}$ has been obtained, this could indicate that both of the isotherms fit the data and in close agreement in respect of adsorption phenomenon. We could think that the Langmuir model would be the only one appropriate in this case but Freundlich gives reliable results as well. The Freundlich model deals with the multilayer adsorption of the substance of the adsorbent. This adsorption isotherm is an indication of surface heterogeneity of the adsorbent while Langmuir type isotherm assume towards surface homogeneity of the adsorbent. The value of $n$ is 3.0423 which indicate favorable immobilization conditions of $\mathrm{Cu}^{2+}$.

Therefore, the results lead to the conclusion that homogenous moieties of stabilizer (CMC) in the nZVI particles suspension might be uniformly distributed on the surface which accounts for both Langmuir and Freundlich adsorption isotherms. However, this finding is inconsistent with the study of Chen and Li [14] who observed that for the Langmuir model $R^{2}$ values are higher $\left(R^{2}=0.9600\right)$ than those of the Freundlich model $\left(R^{2}=0.5600\right)$ in adsorption study of $\mathrm{Cu}^{2+}$ using iron oxide (goethite and hematite).

\subsection{SCANNING ELECTRON MICROSCOPY/ENERGY DISPERSIVE X-RAY (SEM-EDX) ANALYSES}

The SEM shows patterns of before (Figs. $3 \mathrm{a}$ and $\mathrm{b}$ ) and after $\mathrm{Cu}^{2+}$ ion absorbed onto CMC-stabilized nZVI particles collected after a 4 hour reaction (Figs. $3 \mathrm{c}$ and b). There were evident corrosions of nZVI suspension, and probable slightly porous and fragile new particles formed on the surface of the collected nZVI particles after freeze drying. The bright spots on the adsorbed particles reflected the prevalent copper deposition. However, during the batch experiments, part of this layer might leach out together with the DI water during sample preparation. After phase separation, a typical black sample changed to fragile brown-yellow layer after 10 days.

EDX analysis was used to evaluate the element content of $\mathrm{Cu}^{2+}$-loaded nZVI particles as shown in Fig. 3e. The composition of the particles was inferred from the SEM images and amplitudes of various EDX peaks. The spectrum was obtained randomly on selected spots on the nZVI surface. Reading from left to right regions, the specimen contains $\mathrm{O}$ and $\mathrm{C}$ attributed to the stabilizer compound, $\mathrm{S}$ from $\mathrm{FeSO}_{4}, \mathrm{Fe}$, addition of negligible $\mathrm{Au}$ (caused by the coating substances), and $\mathrm{Cu}$ spectra at $7-8 \mathrm{keV}$. The low spectra of $\mathrm{Fe}$ and $\mathrm{Cu}$ indicate that the particle is very small and amorphous. This condition might be due to the injected concentration of $\mathrm{Cu}$ which was too low to be detected by the instrument. The SEM-EDX spectrum also reflects the electro-chemical separation of iron and copper. At the anodic site, the surface layers of nZVI particles were passivated, whereas the copper ions precipitated at the cathodic sites after undergoing a reduction process [26]. However, this result does not agree with findings of Rangsivek and Jekel [26] who obtained intensive spectra showing that $\mathrm{Cu}$ is in crystalline form as proved by their XRD analyses. 

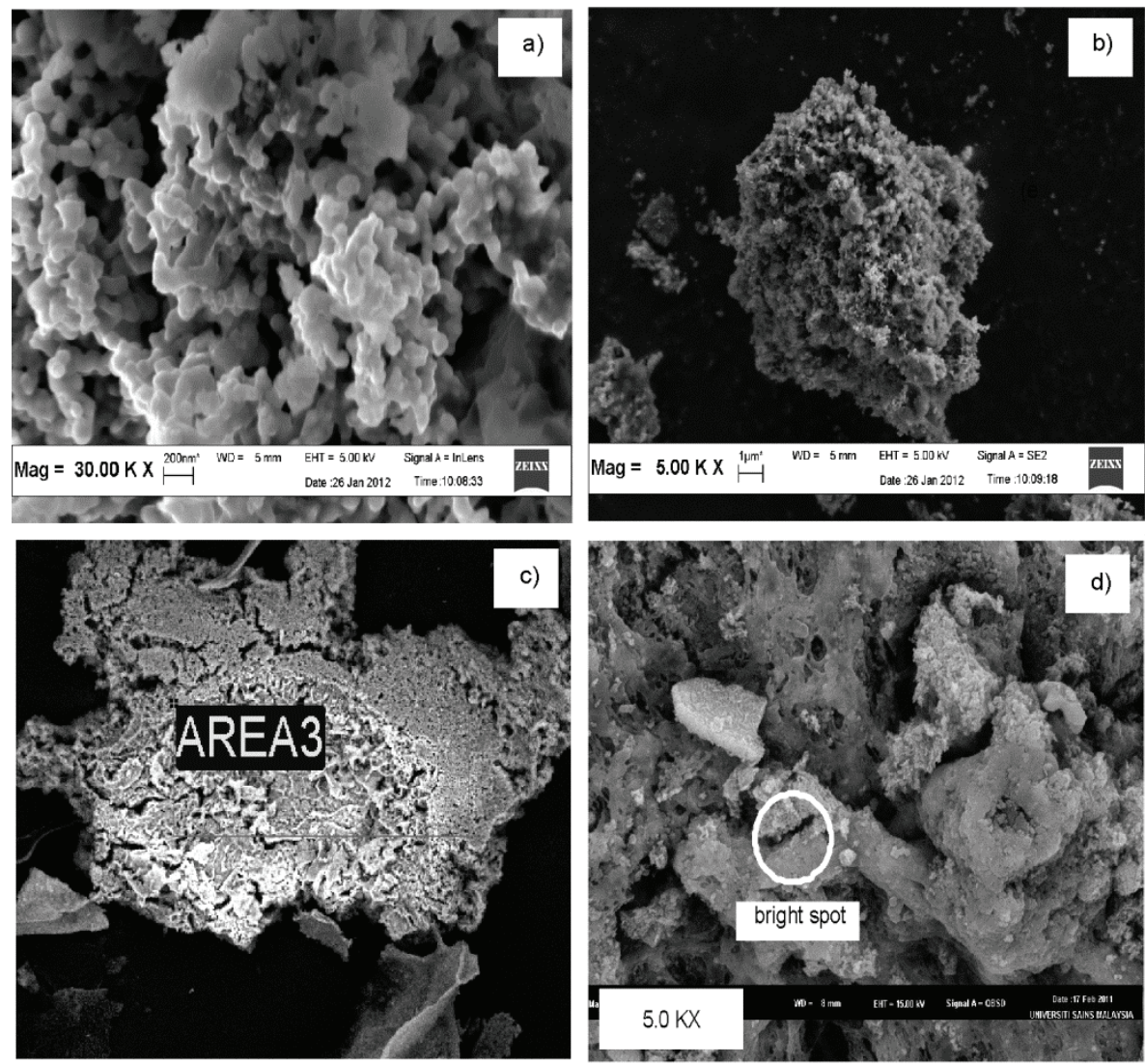

100, Plectron Inage 1

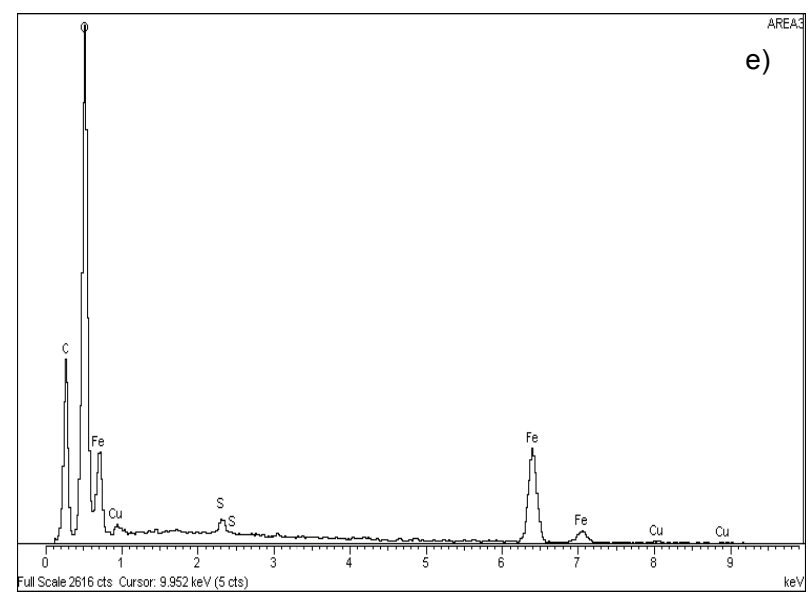

Fig. 3. SEM images of CMC-nZVI particles before reaction (a), b), images of $\mathrm{Cu}^{2+}$ absorbed onto CMC-stabilized nZVI surface, c), d) EDX mapping of adsorbed $50 \mathrm{mg} / \mathrm{C} \mathrm{Cu}^{2+}$ on $1.0 \mathrm{~g} / 1 \mathrm{nZVI}$ suspension at $\mathrm{pH} 6.5, \omega=150 \mathrm{rpm}$, for $240 \mathrm{~min}$ reaction time (e) 


\section{CONCLUSIONS}

The present study demonstrates that CMC-stabilized nZVI particles remain reactive and exhibit greater immobilization efficiency than those prepared without stabilizers. Further, the stability of these nanoparticles against atmospheric elements can be maintained over extended periods of time. The appreciably stabilized nZVI particles and a stable mechanism to remain in suspension should translate into improved immobilization of pollutants. $\mathrm{Cu}^{2+}$ removal was examined using $\mathrm{CuSO}_{4} \cdot 5 \mathrm{H}_{2} \mathrm{O}$ as the model contaminant under various sets of experimental conditions. The concentration of CMC-stabilized nZVI particles demonstrated the highest significant effect on the immobilization of $\mathrm{Cu}^{2+} . \mathrm{Cu}^{2+}$ removal efficiency almost achieved a maximum at $98.10 \%$ when the concentration of nZVI increased to $2.0 \mathrm{~g} / \mathrm{l}$. The reaction was performed within a broad $\mathrm{pH}$ range, and the removal efficiency increased significantly with decreasing initial $\mathrm{pH}$ solution at mild acidity. Hence, CMC-stabilized nZVI particles prepared in the present study were able to sequester and simultaneously remove $\mathrm{Cu}^{2+}$ ions in aqueous solutions.

\section{ACKNOWLEDGEMENTS}

Funding from PRGS (USM) grant No. 1001/PTEKIND/842002 is gratefully acknowledged.

\section{REFERENCES}

[1] Xu Y., Zhao D., Environ. Sci. Technol., 2005, 39 (7), 2369-2375.

[2] Pandey P., Sambi S.S., Sharma S.K., Singh S.P., World Congress Eng. Comp. Sci. (WCECS), Oct. 20-22, 2009, (1), 122-127, San Francisco, USA.

[3] Karabelli D., Uzum C., Shahwan T., Eroglu A.E., Scott T.B., Hallam K.R., Lieberwirth I., Ind. Eng. Chem. Res., 2008, 47 (14), 4758-4764.

[4] Kanel S.R., Greneche J.M., Choi H., Environ. Sci. Technol., 2006, 40 (6), 2045-2050.

[5] Hou M., Wan H., Lui T., FAn Y., Lui X., Wang X., Appl. Catal. B-Environ., 2008, 84 (1-2), 170-175.

[6] Abdulrasaq O.O., Basiru O.G., Afc. J. Env. Sci. Tech., 2010, 4 (6), 382-387.

[7] Rafatullah M., Sulaiman O., Hashim R., Ahmad A., J. Hazard. Mater., 2009, 170, 969-977.

[8] Ahmad A., Rafatullah M., Sulaiman O., Ibrahim M.H., Chit Y.Y., SidDique B.M., Desalination., 2009, $247(1-3), 636-646$.

[9] Ajmal M., Khan A.H., Ahmad S., Ahmad A., Water Res., 1998, 32 (10), 3085-3091.

[10] Rocha C.G., Zaia D.A.M., Alfaya R.V.S, Alfaya A.A.S., J. Hazard. Mater. 2009, 166 (1), 383-388.

[11] Salamatinia B., Kamaruddin A.H., Abdullah A.Z., J. Appl. Sci., 2007, 7 (15), 2020-2027.

[12] WANG Q., SNYder S., Kim J., Choi H., Environ. Sci. Technol., 2009, 43 (9), 3292-3299.

[13] Kumpiene J., Ore S., Renella G., Mench M., Lagerkvist A., Maurice C., Environ. Pollut., 2006, 144 (1), 62-69.

[14] Chen Y.H., Li F.A., J. Colloid Interface Sci., 2010, 347, 277-281.

[15] Kim H.J., Phenrat T., Tilton R.D., Lowry G.V., Environ. Sci. Technol., 2009, 43 (10), 3824-3830.

[16] Sun Y.P., Li X.Q., Zhang W.X., Wang H.P., Colloid. Surf. A: Physicochem. Eng. Aspects., 2007, $308(1-3), 60-66$. 
[17] Sakulchaicharoen N., O’Carroll D.M., Herrera J.E., J. Contam. Hydrol., 2010, 118, 117-127.

[18] Kanel S.R., Goswami R.R., Clement T.P., Barnett M.O., Zhao D., Environ. Sci. Technol., 2008, $42(3), 896-900$.

[19] He F., Zhao D., Lui J., Roberts C.B., Ind. Eng. Chem. Res., 2007, 46 (1), $29-34$.

[20] LeE Y.C., Kim C.W., LeE J.Y., ShIN H.J., YANG J.W., Desalination Water Treatment, www.deswater.com, 2009, 10, 33-38.

[21] Low L.W., Teng T.T., Ahmad A., Morad N., Wong Y.S., Water Air Soil Pollut., 2011, 218 (1-4), 293-306.

[22] Hall K.R., Eagleton L.C., Acrivos A., Vermeulen T., Ind. Eng. Chem. Fundam., 1966, 5 (2), 212-223.

[23] Diallo M.S., Balogh L., Shafagati A., Johnson J.H., Goddard W.A., Tomalia D.A., Environ. Sci. Technol. 1999, 33 (5), 820-824.

[24] Ottaviani M.F., Bossmann S., Turro N.J., Tomalia D.A., J. Am. Chem. Soc., 1994, 116 (2), 661671.

[25] Li X.Q., Zhang W.X., J. Phys. Chem. C., 2007, 111 (19), 6939-6946.

[26] RANGSIVEK R., JEKEL M.R., Water Res., 2005, 39 (17), 4153-4163.

[27] Cissoko M., Zhang Z., Zhang J., Xu X., Process Saf. Environ., 2009, 87 (6), 395-400.

[28] Cundy A.B., Hopkinson L., WhitBy R.L.D., Sci. Total Environ., 2008, 400, 42-51.

[29] Wang Q., Qian H., Yang Y., Zhang Z., NAman C., Xu X., J. Contam. Hydrol., 2010, 114, 35-42.

[30] Zhao D., Sengupta A.K., Ind. Eng. Chem. Res., 2000, 39 (2), 455-462.

[31] Wu Y.J., Zhang J.H., Tong Y.F., XU X.H., J. Hazard. Mater., 2009, 172, 1640-1645.

[32] Uhlig H.H., Revie R.W., Corrosion and Corrosion Control, Wiley, New York, 1985. 